\title{
Reimbursement for Pharmacy Cognitive Services: Insurànce Company Assessment
}

\author{
David M. Scott and Lucinda G. Miller
}

\section{OBJECTIVE:}

To assess the willingness of insurance carriers to reimburse for pharmaceutical care and to determine the extent and success of the Pharmacist Care Claim Form (PCCF) used in obtaining reimbursement.

\section{DESIGN:}

A nine-item survey addressing the PCCF (compiled by the National Community Pharmacists Association, formerly the National Association of Retail druggists. Reimbursement was sent to a random sample of insurance carriers including Blue Cross/Blue Shield, health maintenance organizations (HMOs), preferred provider organizations (PPOs), and commercial insurance companies.

\begin{abstract}
RESULT:
Overall, 116 of $311(37.3 \%)$ surveys were returned (Blue Cross, $57.4 \%$; HMOs, $41.6 \%$; PPOs, $30.7 \%$; and commercial carriers, $27.0 \%$ ). Of insurance carriers, $6.9 \%$ of 116 respondents reported they had reimbursed pharmacists for nondispensing activities. Two carriers reported reimbursement for "monitoring of drug therapy" and "prescription counseling." Only two health insurance carriers reported reimbursement to pharmacists using the PCCF (an HMO and a commercial carrier). Requirements for payment for nondispensing (pharmaceutical care) activities were solicited. Some carriers believe their reimbursement formula takes into consideration all aspects of pharmacist services, reflecting a considerable deficit in their comprehension of phar-
\end{abstract}

maceutical care activities. Other carriers expressed interest, but also demanded evidence that cognitive services result in reducing health expense.

\section{CONCLUSION:}

Future efforts need to focus on motivating community pharmacists to document cognitive services, apply cost-effectiveness methods to evaluate their impact, and educate the insurance carriers about the value and range of pharmacy cognitive services.

\section{KEY WORDS:}

Pharmaceutical care, Pharmacist, care claim form, Intervention form, Documentation, Questionnaire, Survey.

\section{J Managed Care Pharm 1997; 3: 46-48; 50-51}

Health care reform remains a leading domestic policy issue. National pharmacy organizations and pharmacy educators have articulated the value and need for pharmaceutical care reform.' Pharmaceutical care is the responsible provision of drug therapy for the purpose of achieving outcomes that improve a patient's quality of life. ${ }^{2}$ Thus, pharmaceutical care describes cognitive services performed by the pharmacist beyond the physical dispensing of a drug product.

As our nation undergoes health care reform, community pharmacists must document their pharmaceutical care activities. Documentation of the community pharmacist's role in providing pharmaceutical care and therapeutic outcomes has been negligible. The Pharmacist Care Claim Form (PCCF) was developed by NARD (now National
Community Pharmacists Association) to help pharmacists carry out the documentation and reimbursement process. PCCF, a three-part carbonless form, first became available in 1994, the year in which this study was conducted. The original (white) copy is submitted to the payer; the second (yellow) is given to the patient; and the third (pink) copy is retained by the pharmacy. ${ }^{3}$ The goal of the PCCF is to provide a uniform document to submit to third-party carriers for reimbursement of pharmaceutical care. Use of this form has not yet been systematically analyzed.

The purpose of this research project is to assess the willingness of insurance companies to reimburse for pharmaceutical care and to determine the extent and success of the PCCF use in obtaining reimbursement. The insurance carriers' receptivity was assessed by determining the per-

Authors

DAVID M. SCOTI", PH.D., M.P.H., R.PH., is Associate Professor; and LUCINDA G. MILLER, PHARM.D., BCPS, is Associate Professor, Department of Pharmacy Practice, University of Nebraska Medical Center, Omaha

CORRESPondence: David M. Scot,, Department of Pharmacy Practice, University of Nebraska Medical Center, 600 South 42nd Street, Omaha, NE 68198-6045

ACKNOwLedements: To the NARD Foundation for financial support to complete this project, as well as the Blue Cross/Blue Shield, HMOs, PPOs, and commercial insurance company/organization participants and their drug benefit specialists who completed our survey; to Miriam Eckblade at UNMC Computing Services for database design; and to Susan Daughton, Pharm.D., who at the time of this study was a doctor of pharmacy student, for her timely and competent organization of the survey mailings and data entry.

Copyright $\odot 1997$, Academy of Managed Care Pharmacy, Inc. All rights reserved. 
centage of third-party carriers who reimburse pharmacy cognitive services, and by determining what specific aspects of pharmaceutical care are not considered reimbursable by the insurance company. This was documented by presenting the PCCF, with an accompanying questionnaire, to insurance carriers to assess their receptivity to the form.

\section{METHODS}

\section{Sample Selection}

To assess the willingness of insurance companies to reimburse for pharmaceutical care, the NARD PCCF was sent nationwide to a random sample of 450 health insurance carriers. A 1994 mailing list of health insurance carriers ${ }^{4}$ was obtained and sorted by commercial insurance companies $(n=877)$, Blue Cross and Blue Shield (Blues) plans $(n=67)$, health maintenance organizations (HMOs) $(n=583)$, and preferred provider organizations (PPOs) $(n=750)$. The random sample of 450 represents $19.8 \%$ of the health insurance carriers nationwide. The sample of commercial health insurance carriers $(n=165)$ included the five largest health insurance companies of the Alliance for Managed Competition (Prudential, Aetna, Cigna, Metropolitan Life, and Travelers), and a random sample of 160 medium- to smaller-size commercial insurance carriers. All Blue Cross and Blue Shield plans $(n=67)$ were included, and a 16\% random sample of $92 \mathrm{HMOs}$ and 124 PPOs was compiled. The survey was sent to the chief executive officer (CEO), with a request to forward this survey to the person in that organization responsible for the prescription drug program.

\section{Survey Design}

A PCCF and a nine-item survey (Figure 1) were sent to detail the carriers' policies concerning reimbursement of pharmacist interventions in drug therapy beyond dispensing. Survey items included respondents' position, who in their company administers the prescription plan, how the outpatient drug plan is reimbursed, and what techniques are used to contain prescription costs. The respondent also was asked if the company had reimbursed pharmacists for pharmaceutical care using the PCCF. Another item asked if the company reimbursed for the pharmacist's time spent on: (1) monitoring of drug therapy and physician referral, (2) prescription counseling, (3) contacting physician for prescription clarification, (4) consulting on self-care/self-medication, and (5) "other." An open-ended response item was added to learn what would be required for the company to consider payment for pharmaceutical care.

\section{Survey Distribution}

Each survey was coded with an identification number, permitting name and address location to help avoid duplicate mailings to respondents. Nonrespondents received a postcard reminder at three weeks. Follow-up phone calls were made to CEOs to enhance their response rate. Second and third mail-
Table 1. Response Rates of Health Insurance Carriers

\begin{tabular}{|c|c|c|c|c|c|}
\hline & $\begin{array}{l}\text { No. } \\
\text { Surveys } \\
\text { Sent }\end{array}$ & $\begin{array}{l}\text { No. } \\
\text { Wrong } \\
\text { Address }^{\text {a }}\end{array}$ & $\begin{array}{l}\text { No. not } \\
\text { Providing } \\
\text { Service }^{b}\end{array}$ & $\begin{array}{l}\text { No. } \\
\text { Valid } \\
\text { Recipients }\end{array}$ & $\begin{array}{l}\text { No. } \\
\text { Completed } \\
\text { Surveys }(\%)^{\mathrm{C}}\end{array}$ \\
\hline \multicolumn{6}{|l|}{ Blue Cross/ } \\
\hline Blue Shield & 67 & 4 & 2 & 61 & $35(57.4)$ \\
\hline Commercial & 165 & 34 & 42 & 89 & $24(27.0)$ \\
\hline HMO & 92 & 16 & 7 & 3 & $30(41.1)$ \\
\hline PPO & 124 & 21 & 15 & 88 & $27(30.7)$ \\
\hline Total & 448 & 75 & 62 & 311 & $116(37.3)$ \\
\hline \multicolumn{6}{|c|}{$\begin{array}{l}\text { No forwarding address } \\
\text { b No longer providing health insurance that includes a drug benefit } \\
{ }^{c} \text { Number of completed surveys returned }\end{array}$} \\
\hline
\end{tabular}

ings of the survey were sent at eight weeks and 12 weeks, respectively, to nonrespondents. The companies were assured that the information provided by the company would be treated confidentially, with only group data used for any reports. All data were entered into an SAS database ${ }^{5}$ using the University of Nebraska Medical Center's IBM mainframe.

\section{RESULTS}

\section{Response Rate and.Respondent's Position}

Responses from incorrect addresses and insurance carriers who reported they no longer provicle health insurance with a drug benefit $(n=62)$ were removed, leaving 311 valid respondents. Of these, 1.16 (37.3\%) usable responses were returned (Table 1). In order of response rate, Blue Cross/Blue Shield (57.4\%) was highest, followed by HMOs (41.1\%), PPOs (30.7\%), and commercial carriers (27.0\%)

Approximately $43.1 \%$ of the surveys were completed by the pharmacy benefits manager (PBM). PBMs were more likely to complete the surveys in Blue Cross/Blue Shield (1.7.2\%), PPO (1.3.8\%), and HMO (8.6\%) plans than in commercial plans (3.5\%). Of the respondents, $47.4 \%$ were listed in the "other" category, including pharmacy directors, health insurance benefits managers, and claims managers. About $7.0 \%$ of the surveys were completed by the CEO in $\mathrm{HMO}$ and PPO plans.

\section{Insurance Carrier Reimbursement Using the PCCF}

Insurance carrier reimbursement to pharmacists for provision of pharmaceutical care via the NARD PCCF was small. One HMO carrier and one commercial carrier reported reimbursement to a pharmacist submitting a claim using the PCCF form.

\section{Insurance Carrier Reimbursement for Cognitive Services of Pharmacists}

Insurance carriers' reimbursement of pharmacist time for selected cognitive services is summarized in Table 2 . These categories of services included "monitoring of drug therapy and referral to a physician," "prescription counseling," 


\section{Figure 1. Insurance Company Assessment Survey}

\section{Your position:}
a. chief executive officer
b. underwriter
c. sales representative
d. pharmacy benefits manager
e. other (specify)

2. Outpatient prescription drug coverage is administered:

a. within the company (organization)

b. by an independent pharmacy claims adminisı rator

\section{Outpatient prescription drug expense plan is a:}

a. reimbursement plan (individual pays then submit claims on a claim form completed by the pharmacist or policyholder for the insurer)

b. service plan (puyment by insurer to provider directly using a small claims third party administrative organization)

c. other (specily):

4. What measures does your company/organization use to contain prescription drug costs: (circle all that apply)

a. drug utilization revicw (DUR)

b. drug formulary

c. generic substitution

d. peer physician to physician drug therapy consulation

c. pharmacist to physicien drug therapy consultation

f. other (specify)

5. Number (or percentage) of health insurance policyholders with coverage for:

a. inpatient prescription drugs

b. outpatient prescription drugs

c. other (specily):

6. Do you reimburse for the pharmacists' time spent on:

\section{No/ Yes If "yes", what} non-dispensing fec do you pay?

a. monitoring of drug therapy and referral to a physician (e.g, adverse effect, allergy, drug interaction)

b. prescription counseling

c. contacting physician for prescription clarification

d. consuling on self-care/self-medication

e. other (specity).

7. Refer to the enclosed NARD Pharmacist Care Claim Form (PCCF) and guide to submitting claims for pharmacist care. Have you reimbursed pharmacists for pharmaceutical care from the NARD Pharmacist Care Claim Form? (Assume that pharmaceutical care includes non-dispensing activities, e.g. patient counseling, physician contact for drug interaction).

a. no

b. yes

8. If you answered "No" to question \#6 and question \#7, what would be required before your company/organization would consider payment for these activities?

9. Number (or percentage) of health insurance policyholders in:

a. indemnity plans

b. HIMO

c. PPO

d. other maraged care plans specify:

e. other, specify:

f. none of the above

Thank you for taking time to complete this survey. Please return in the envelope provided.
Table 2. Insurance Carriers Reimbursement for Pharmacist Time

\begin{tabular}{llllll}
\hline Pharmacist Activity & BC/BS & PPO & HMO & Commercial & Total \\
\hline $\begin{array}{l}\text { Monitoring of } \\
\text { drug therapy } \\
\text { and referral } \\
\text { to a physician }\end{array}$ & $1(0.9)$ & $0(0)$ & $1(0.9)$ & $0(0)$ & $2(1.7)$ \\
$\begin{array}{l}\text { Prescription } \\
\text { counseling }\end{array}$ & $1(0.9)$ & $0(0)$ & $1(0.9)$ & $0(0)$ & $2(1.7)$ \\
$\begin{array}{l}\text { Contacting } \\
\text { physician for } \\
\text { prescription } \\
\text { clarification }\end{array}$ & $0(0)$ & $0(0)$ & $1(0.9)$ & $0(0)$ & $1(0.9)$ \\
$\begin{array}{l}\text { Consulting on } \\
\text { self-caref } \\
\text { self-medication }\end{array}$ & $0(0)$ & $0(0)$ & $1(0.9)$ & $0(0)$ & $1(0.9)$ \\
\begin{tabular}{l} 
Other \\
\hline \begin{tabular}{l} 
Total \\
\hline
\end{tabular}
\end{tabular} & $1(0.9)$ & $0(0)$ & $1(0.9)$ & $0(0)$ & $2(1.7)$ \\
\hline
\end{tabular}

"contacting physician for prescription clarification," "consulting on self-care/self-medication," and "other." Overall, $6.9 \%$ of insurance carrier ( 8 of 116 ) respondents reported they had reimbursed pharmacists for nondispensing activities. Two carriers reported reimbursement of pharmacists for "monitoring of drug therapy" and for "prescription counseling." The remaining three cognitive service categories had one carrier each reporting reimbursement. The most likely insurance carriers to provide pharmacist reimbursement were HMOs and Blue Cross/Blue Shield.

\section{Insurance Carrier Requirements for Reimbursement for Cognitive Services of Pharmacists}

Insurance carriers' comments were requested regarding their requirements for payment for pharmaceutical care. Pharmaceutical care was operationally defined for the carriers as including nondispensing activities (e.g., patient counseling, physician contact for drug interaction). One written comment characterized a common misconception: "Our reimbursement formula takes into consideration all aspects of pharmacists' services."

Most insurance carriers require a demonstration that pharmaceutical care results in cost savings from improved patient outcomes. Sample responses were, "Demonstration of cost-effective outcomes for pharmacist interventions," "documentation of savings to plan," "demonstration that cognitive service reimbursement works-there have been a few small studies, but no large studies that I am aware of," "a reduction 
of costs elsewhere in the medical expense dollar to obtain a net savings," and "demonstration of cost savings that service is above what they are currently paying for."

One carrier summarized the general attitude of insurance carriers: "We are very interested in such a program, but need good data to support the resulting savings; we have encouraged pharmacists to provide these data." On a positive note, another carrier expressed, "We plan to have a reimbursement program in place next year for pharmacists-this will be handled through our pharmaceutical managed care organization."

\section{Administration of a Prescription Drug Plan}

In recent years, many health insurance plans have turned to PBMs to administer the prescription drug component of their health insurance plan. We therefore included an item to assess how the prescription drug plan was administered by health insurance carriers. Of outpatient prescription coverage, $48.6 \%$ was administered by an independent pharmacy claims administrator and $50.5 \%$ within the organization. Administration of prescription drug plans has been shifting toward contracting with independent pharmacy claims administrators. Approximately half the plans, however, were still administered within the insurance organization. Commercial carriers were less likely than the other three insurance carrier types to administer claims using an independent pharmacy claims administrator (Table 3).

A service plan is operationally defined as one in which the provider bills and collects payment directly using a smallclaims, third-party administrative organization. Reimbursement plans are operationally defined as those in which the policyholder pays for the prescription and then submits a claim form for prescription cost reimbursement. A service plan was used by $58.5 \%$ of respondents using the prescription payment method and another $25.9 \%$ used a reimbursement plan. As reported in Table 3, service plans were more likely to be used by HMOs (21.4\%), PPOs (15.7\%) and Blue Cross/ Blue Shield plans (13.5\%). Commercial carriers were more likely to use a reimbursement plan than a service plan. By analyzing the "other" category for respondents' open-ended comments, some of those plans cited alternative payment plans as staff-model HMOs, mail order, and point-of-service plans.

\section{Measures Used by Carriers to Contain Prescription Drug Costs}

Commercial insurance carriers have attempted various measures to contain prescription drug costs. In this survey, generic substitution ( $46.8 \%$ ) was the most commonly used cost-containment measure, followed by drug-use review (DUR) $(26.7 \%)$. Of the four carriers, commercial insurance carriers were most likely to use generic substitution, DUE, and formulary control. A combination of measures was reported by 90 of the respondents. All five categories were used by $21.1 \%$ of carriers. Three measures-DUR, drug formulary, and generic substitution-were used by $20.0 \%$ of the carriers. These three measures were combined with "pharmacist-to-
Table 3. Administration of Insurance Carriers' Outpatient Prescription Coverage

\begin{tabular}{lcccccr}
\hline & \multicolumn{5}{c}{ No. Respondents (\%) } \\
& BC/BS & PPO & HMO & Commercial & Total \\
\hline $\begin{array}{l}\text { Within the } \\
\text { organization }\end{array}$ & $17(1.4 .8)$ & $12(10.4)$ & $12(1.0 .4)$ & $15(13.0)$ & $56(48.6)$ \\
$\begin{array}{l}\text { Independent } \\
\text { pharmacy claims } \\
\text { administrator }\end{array}$ & $17(1.4 .8)$ & $15(13.0)$ & $18(1.5 .7)$ & $8(7.0)$ & $58(50.5)$ \\
$\begin{array}{l}\text { Other } \\
\text { Total }\end{array}$ & $1(0.9)$ & $0(0)$ & $1(0.9)$ & $0(0)$ & $1(0.9)$ \\
\hline
\end{tabular}

physician drug therapy consultation" by $16.7 \%$ of carriers. Another $5.6 \%$ reported a combination of the three measures and "peer physician-to-physician drug therapy consultations."

\section{DISCUSSION}

\section{Major Findings}

This research project was designed to assess the willingness of insurance companies to reimburse for pharmaceutical care and estimate the extent and success of the PCCF use. The PCCF was developed to help pharmacists carry out the documentation and reimbursement process. However, only $2.8 \%$ of pharmacists surveyed reported that they regularly documented these activities using the PCCF. Thus, very few pharmacists were using the PCCF to document nondispensing activities, and resulting reimbursement is minimal.

Based on the findings of this assessment, insurance carriers are not providing reimbursement to the pharmacist via PCCF for cognitive services. Only $7.7 \%$ (7 of 159) of insurance carriers have provided reimbursement to pharmacists for nondispensing activities. Only two carriers-an HMO and one commerical insurer-reported reimbursement by route of the NARD-developed PCCF. The low reimbursement rate by insurance carriers is partially explained by the lack of pharmaceutical care interventions documentation by the pharmacist.

\section{Implications}

One major implication of our study is reflected in the comments of one insurance carrier: "Our reimbursement formula takes into consideration all aspects of pharmacist services." The pharmacy profession needs to use tools (e.g., PCCF) to document these interventions. Rhetoric by pharmacy leadership may provide motivation to change behaviors, but it is only through empiric evidence and education of insurance carriers that major change in reimbursement will take place. Currently, little empiric evidence supports the notion that pharmacists are providing cost-effective pharmaceutical care. Pharmacists need to re-examine their attitudes and document their activities. Since our nation is undergoing health care reform and increased accountability, community pharma- 
Table 4. Insurance Carriers Prescription Claims Method

\begin{tabular}{|c|c|c|c|c|c|}
\hline & \multicolumn{5}{|c|}{ No. Respondents $(\%)$} \\
\hline & $\mathrm{BC} / \mathrm{BS}$ & PPO & HMO & Commercial & Total \\
\hline $\begin{array}{c}\text { Reimbursement } \\
\text { method }^{a}\end{array}$ & $7(7.9)$ & $5(5.6)$ & $0(0)$ & $11(12.4)$ & $23(26.1)$ \\
\hline Service methodb & $12(13.5)$ & $1.4(15.7)$ & $19(21.4)$ & $7(7.9)$ & $52(59.1)$ \\
\hline Olher ${ }^{\mathrm{C}}$ & $4(4.5)$ & $3(3.4)$ & $6(6.7)$ & $0(0)$ & $13(14.8)$ \\
\hline Total & $23(25.9)$ & $22(24.7)$ & $25(28.1)$ & $18(20.3)$ & $88(100.0)$ \\
\hline
\end{tabular}

a Policyholder pays then submits claims on prescription claim form

b Pharmacist bills and collects payment directly using a small claim third-party administrative organization

c Other, such as mail-service pharmacies

cists must document their pharmaceutical care activities if they expect to maintain the current level of remuneration. Without remuneration for cognitive services, any future level of pharmaceutical care will be questionable and perhaps fiscally impossible.

A second implication of this study was expressed by another carrier: "We are very interested in such a program, but need good data to support the resulting savings; we have encouraged pharmacists to provide these data." While insurance carriers are willing to examine payment for pharmaceutical care, they also demand evidence that cognitive services result in cost savings. This study implication should provide a major challenge to NARD and other national pharmacy organizations. NARD has supported efforts to design the PCCF Pharmacy educators and leaders must now convince pharmacists to document pharmaceutical care activitics. In the final analysis, it is ultimately the pharmacist's individual responsibility to document interventions and hence, build a bridge to pharmacy's future.

A third implication of this study is that pharmaceutical care training programs for community pharmacists must be encouraged to train pharmacists to provide patient-oriented services and to document these services. The PCCF is best used when integrated into existing pharmacy computer software packages so pharmacists can easily record, organize, and submit pharmaceutical care claims to insurance carriers. Since the study was conducted, the PCCF has been revised and includes the following enhancements: incorporation of the National Council for Prescription Drug Programs (NCPDP) Professional Pharmacy Service Codes (recognized by thirdparty processors), addition of a "level of service" field (allows time and intensity of effort), National Drug Code (NDC) fields (specific drug identification number), and a certification statement (such as pharmacist disease management certification). The new form is available from Med-Pass, Inc. (Dayton, Ohio). A computerized version is now available from QARx
Software System. ${ }^{\circ}$ While these efforts have been made, the PCCF form is still not integrated into common pharmacy processing software. PBMs could ease this problem through simple electronic access through claims adjudication systems. Pharmacist time should be focused on patient care and not unnecessary duplicitous documentation efforts. Training community pharmacists and pharmacy students in pharmaceutical care and its documentation is essential. This training must focus on the needs of the patient and ensure that appropriate clinical and managerial follow-up support is provided to ensure pharmacist success.

The fourth implication of this study is researchers' need to focus pharmacoeconomic methods on the assessment of the cost-effectiveness of these pharmaceutical care efforts. Community pharmacists must document pharmaceutical care interventions and associated positive therapeutic outcomes. Cost-analysis techniques then should be applied to show cost savings and lowering of the overall health care expense.

\section{CONCLUSION}

While the investigators do not advocate the PCCF as the only documentation instrument, we suggest that a universal claim form be developed and used to submit claims for pharmaceutical care. This study was conducted in 1994, the first year the PCCF was available. With pharmacist training in pharmaceutical care, combined with greater adoption of a documentation form by both pharmacists and insurance carriers, the investigators expect that use of the PCCF or another documentation form will substantially increase in the future. Given these trends, this insurance company assessment should be re-evaluated periodically and the results compared with these baseline results.

\section{A References}

1. Coalition for consumer access to pharmaceutical care: an invitation to action. Washington, DC: Coalition for Consumer Access to Pharmaceutical Care, 1994: 1-6.

2. Hepler CD, Strand LM. Opportunities and responsibilities in pharmaceuilcal care. Am J Hosp Pharm 1990; 47: 533-43.

3. Anonymous. How 10 use NARD's pharmacist claim form. Symposium on documenting the value of your profcssional pharmacy services: a system that works. Presented at NARD's 95 th Annual Convention and Trade Exposition, Indianapolis, Indiana, 1993 (Ocl 26).

4. Backus K. Medical and health information direciory, 1992-93: 51.5-8,

519-47, 549-67, 569-92.

5. SAS/STAT user's guide, version 6. 4th ed. Cary, NC: SAS Institute, 1988 (859): 1634

6. Scou DM, Miller LG. Reimbursement for pharmacy cognilive services: pharmacist assessment. Final report. Alexandria Virginia: NARD Foundation 1995: 14

7. Bluml B. QARx software system, version 4.0. Washington, DC: Cygus Systems Development, Inc. and American Pharmaceutical Association, 1994 